\title{
Building a Latin American cancer patient advocacy movement: Latin American cancer NG0 regional overview
}

\author{
Alessandra Durstine, MBA, MS, ${ }^{(1)}$ Elizabeth Leitman, MPH, MIA. ${ }^{(2)}$
}

\begin{abstract}
Durstine A, Leitman E. Building a Latin American cancer patient advocacy movement: Latin American cancer NGO regional overview. Salud Publica Mex 2009;5I suppl 2:S3I6-S322.
\end{abstract}

\begin{abstract}
The objective of the this paper is to assess and identify the key strengths and weaknesses for cancer control NGOs in Latin America, with the goal to make recommendations about how to improve thev impact of the patient advocacy movement as it pertains to cancer. The methods included literature review, expert interviews and site visits to Latin American cancer hospitals and NGOs. The overall findings conclude that NGOs currently do not take a leadership role in cancer control in Latin America. The lack of a survivorship movement, faulty patient information services and failure of the governments to include NGOs in policy creation are identified as areas for further project work and collaboration. The stigma of cancer still remains and a burgeoning patient movement can be created to help destigmatize and debunk the myths that surround cancer.
\end{abstract}

Key words: patient advocacy; cancer; NGO; policy making; survivorship
Durstine A, Leitman E.

Desarrollando un movimiento de apoyo para pacientes de cáncer en America Latina: resumen regional -ONGs de cáncer.

Salud Publica Mex 2009;5I supl 2:S316-S322.

\section{Resumen}

El objetivo de este artículo es el de identificar y evaluar las fortalezas y debilidades clave de las ONG dedicadas al control del cáncer en Latinoamérica, con el fin de generar recomendaciones sobre el modo de mejorar el impacto del movimiento de apoyo para pacientes de cáncer. Los métodos incluyeron una revisión de la literatura, entrevistas a expertos y visitas a hospiptales y ONG dedicados al cáncer en Latinoamérica. Los hallazgos principales permiten concluir que en este momento las ONG no tienen un rol de liderazgo para el control del cáncer en Latinoamérica. La ausencia de un movimiento de sobrevivientes, servicios de información deficientes a los pacientes y el fracaso del gobierno para incluir a las ONG en la creación de políticas se identifican como áreas de trabajo y colaboración en proyectos a futuro. El estigma del cáncer aún subsiste y es factible crear un movimiento que florezca y ayude a desvanecerlo al exponer los mitos que rodean este padecimiento.

Palabras clave: defensa del paciente; cáncer; ONG; política; formulación de políticas, sobrevivencia
$\mathrm{T}$ he objective of this paper is to summarize the findings of the American Cancer Society's (ACS) 6 month market research of NGOs and civil society in ten countries in Latin America: Argentina, Brazil, Chile, Colombia, Costa Rica, Ecuador, Mexico, Peru, Uruguay and
Venezuela. The ACS selected 10 countries and conducted interviews with policymakers, NGO representatives, key opinion leaders and other stakeholders in order to gather data on the following: 1) Identify the lead NGOS involved in cancer control; 2) overall strengths

(I) American Cancer Society.

(2) Independent consultant.

Received on: November 3,2008 - Accepted on: December 19,2008 Address reprint request to: Alessandra Durstine. American Cancer Society. I599 Clifton Road Ne. Atlanta, GA 30329-425I. E-mail: alessandra.durstine@cancer.org 
and weaknesses of Latin American NGOs committed to fighting cancer, and 3) recommendations for next steps in strengthening NGOs in order to increase their impact on cancer control.

The World Health Organization (WHO) projects that over the next 25 years, the worldwide burden of disease will shift from infectious disease to non-communicable disease. ${ }^{1}$ Cancer will be the world's leading cause of death in 2010. Despite this trend of non-communicable disease becoming the leading cause of global deaths, many national governments have been hesitant to embrace comprehensive policies that address non-communicable diseases such as cancer. In a WHO survey of over 167 countries in 2001, only a few countries reported they had developed comprehensive cancer control programs that included prevention, early detection, treatment, and palliative care. ${ }^{2}$

In Brazil, the National Cancer Institute (INCA) is formally recognized as a technical branch of the federal government and is entrusted with developing Brazil's national cancer control plan. Engaging Brazil's civil society has already been identified as a necessary element for this plan's success. ${ }^{3}$ Successful engagement between a country's civil society stakeholders and policy-makers is crucial if cancer policy is to meet the true needs of the society.

Cancer patient organizations play a very important role in mobilizing cancer control initiatives. These organizations have helped disseminate accurate information to underserved communities, created support programs that link cancer survivors with cancer patients, and promoted the early detection of cancer. ${ }^{4}$ By engaging key stakeholders, such as health professionals, legislators, and community leaders, cancer patient organizations help establish cancer control as a national public health priority. Although many cancer patient organizations operate with modest budgets, they often run very successful programs thanks to their talented and committed volunteer base. By contributing their time and skills, volunteers can make a great difference in their national cancer control movements. The American Cancer Society, for example, counts on the help of more than 3 million volunteers in the United States in working to achieve its goals. ${ }^{5}$

Cancer survivors are vital to the success of a cancer control movement. The American Cancer Society relies on the contributions of survivors to achieve its mission and cancer control goals. By providing a "face" and a "voice" to the cancer experience, cancer survivors have been crucial in the process of mobilizing civil society and destigmatizing cancer. In some countries, cancer is often viewed as a "death sentence," with a culture of silence surrounding the disease. By sharing their patient experi- ences with the public, cancer survivors have been able to promote open and public dialogue. These survivor stories motivate others to adopt lifestyle behaviors that help reduce cancer risk, and encourage lifesaving early detection.

Cancer is a political issue, as well as a medical, psychological, social, and economic issue. Life and death decisions about cancer are made every day not just in the doctor's office but also in the offices of policy-makers. For this reason, the American Cancer Society is committed to helping enhance the role of cancer control NGOs in developing countries through capacity building in areas such as fundraising, volunteer recruitment, and cancer control advocacy. These activities are designed to mobilize civil society and position cancer control NGOs as leaders in advocating governments in their countries to develop policies to address the growing cancer burden.

\section{Material and methods}

This report is a scan of cancer patient groups and oncology networks in ten countries in Latin America: Argentina, Brazil, Chile, Colombia, Costa Rica, Ecuador, Mexico, Peru, Uruguay and Venezuela. The countries were selected based on the trends in infectious disease trends versus chronic disease trends. ACS selected countries which were trending towards chronic disease which would indicate that cancer will be a more serious disease burden in the future.

American Cancer Society staff and consultants gathered data on the following: strengths and weaknesses of national healthcare systems and governmental commitment to cancer control and treatment; existence of patient groups and NGOs committed to fighting cancer; institutional capacity and strengths and weaknesses of selected patient groups, NGOs and government entities involved in cancer control; and recommendations for next steps in strengthening civil society to enhance cancer control capacity from a patient-driven perspective. The NGOs selected are either the largest or most recognized NGOs in the areas of awareness, coalition building or emotional support since ACS has the experience of showing that these strengths are pre-indicators for ability to implement policy advocacy programs.

This report was developed through the following process:

1. Country selection: Ten priority countries were selected for analysis in the region including: Argentina, Brazil, Chile, Colombia, Costa Rica, Ecuador, Mexico, Peru, Uruguay and Venezuela. 
2. Consultant selection and NGO interview process: A team of 6 consultants was recruited, hired and trained to research the cancer NGO landscape in the selected countries. Relying upon the recommendations of key informants in-country, the consultant team identified the most promising 6-11 cancer NGOs in each country and conducted interviews with NGO representatives, utilizing the ACS institutional analysis instrument (table I), which had been specifically formulated for this project. A component of the interviews involved NGOs conducting a self-assessment of their institutional strengths and weaknesses in a variety of programmatic and management areas.

3. Compilation of NGO information: After the interviewing process, the consultants compiled institutional information about each NGO and wrote reports detailing and assessing the institutional capacity of each in the following areas: mission, governance/ management and staffing, budget/fundraising, and program and advocacy work.

4. Identification of top cancer NGOs per country: The consultant team then identified the strongest 2-6 groups in each country as strategic choices for partners for

TABLE I

ACS Institutional Analysis Tool

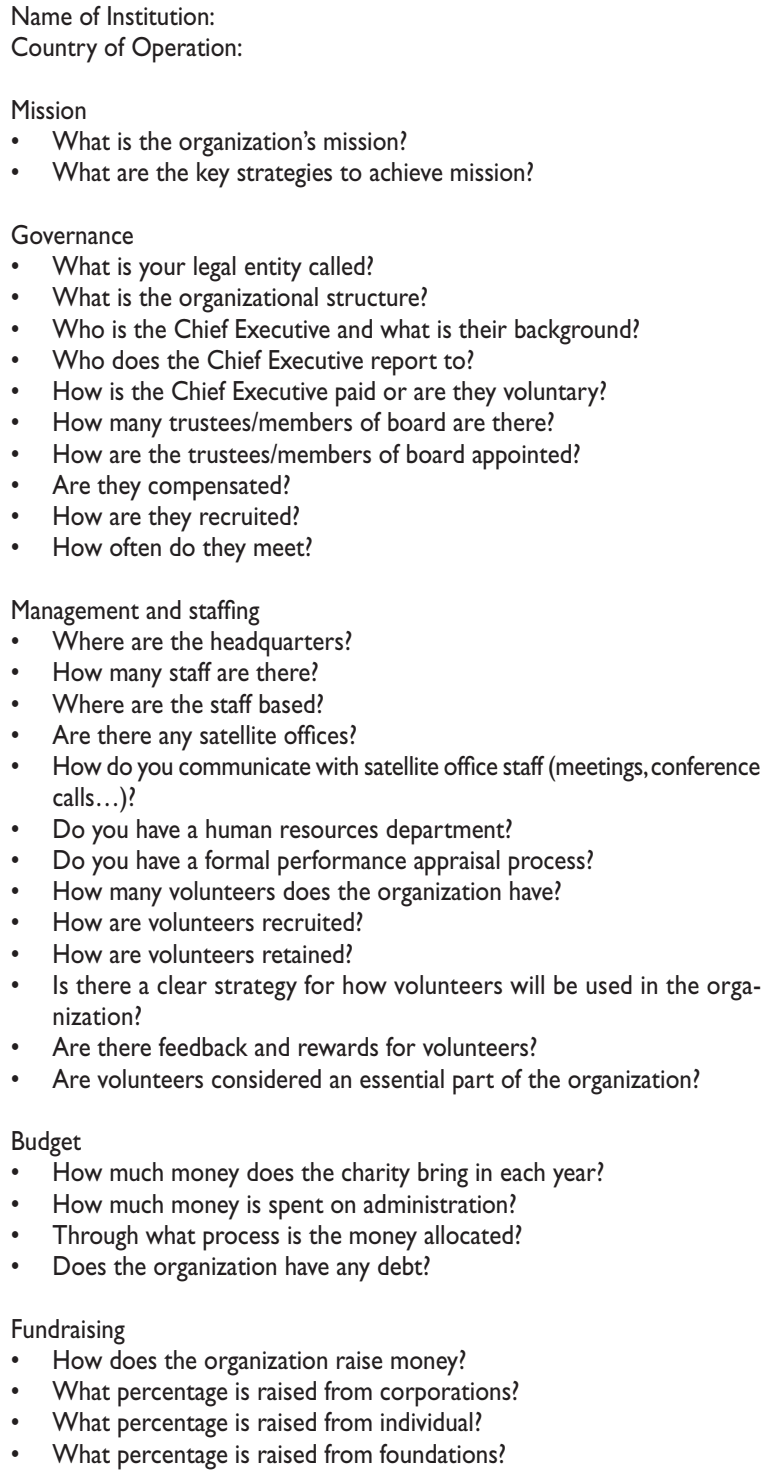

- Are there feedback and rewards for volunteers?

- Are volunteers considered an essential part of the organization?

Budget

- How much money does the charity bring in each year?

- How much money is spent on administration?

- Through what process is the money allocated?

- Does the organization have any debt?

Fundraising

- How does the organization raise money?

- What percentage is raised from corporations?

- What percentage is raised from individual?

- What percentage is raised from foundations?

- What percentage is raised from the government?

- What percentage comes from outside of your country?

- Do you have a database of supporters?

- If so, how many supporters do they have on their records?

- Is there a fundraising strategy?

- Does the organization have long term fundraising goals?

- Do you have reserve funds to support operations if funding sources are lost?

- Is there accountability for the use of funds?

Programs

- What is the main focus of the group's activities?

- What percentage of the funds goes to each program?

- What programs do they run?

- Are they national or local?

- Are they staff-led or volunteer-led?

- How do you work with local media?

- Do you have staff dedicated to working with the media?

- Who makes decisions about program implementation?

Community Involvement

- What are community perceptions of the organization?

- Are attempts made to solicit community feedback on the effectiveness of programs?

- Is the community involved in needs assessments or planning activities?

- What proportion of the target population is reached by the organization's activities?

Evaluation

- Does the organization conduct periodic self-assessments?

- Are all levels of organization (governing board, staff, volunteers) involved in the evaluation process?

- Are organizational self-assessments tied to decision making processes relating to future goals and activities?

- Are individual programs evaluated for effectiveness?

Advocacy

- Do you have specific programs designed to make an impact on national policy?

- What is the nature of your relationship with policy makers, if any?

- Can you site any examples of advocacy success by your organization or others?

- Does your organization partner with other organizations to achieve advocacy goals? 
TABLE II

Recommendations for parthership by country

Country

Organization

Activities to support breast cancer

\begin{tabular}{lll} 
Argentina & Liga Argentina de Lucha Contra el Cáncer- (LALCEC) & Advocacy, awareness, emotional support \\
& MACMA & Emotional support \\
& Fundación para la Investigación y Prevención del Cáncer & Awareness, research \\
\hline Brazil & IMAMA & Coalition, advocacy \\
& AMUCC & Awareness, emotional support \\
& ABCancer & Awareness, policy \\
\hline Chile & Corporación Nacional del Cáncer (CONAC) & Emotional support \\
\hline Colombia & Liga Nacional de Lucha contra el Cáncer (LNLC) & Awareness, emotional support, advocacy \\
& AMESE & Emotional support, awareness, adovcacy \\
\hline Costa Rica & Dra. Ross Program & Emotional support \\
& Fund. Nacional de Solidaridad contra el Cáncer de Mama & Emotional support \\
\hline Ecuador & Instituto de Cáncer de SOLCA Núcleo de Cuenca & Emotional support \\
\hline Mexico & Grupo Reto & Emotional support, awareness \\
& Fundación CIMA*B & Emotional support, awareness \\
& Asociación Mexicana De Lucha Contra El Cáncer & Awareness \\
\hline Peru & Liga Peruana de la Lucha Contra el Cancer & Emotional support \\
& Esperantra & Emotional support \\
\hline Uruguay & Comisión Honoraria de Lucha contra el Cáncer & Awareness \\
& Programa Nacional de Control del Cáncer- PRONOCAN & Advocacy \\
\hline Venezuela & Senosayuda & Coalition, advocacy, awareness, support \\
& SenoSalud & Awareness, emotional support \\
\hline & &
\end{tabular}

collaborative initiatives (table II, Recommendations for partnership by country).

5. Formulation of final reports and recommendations: ACS provided ongoing supervision and support to consultants, including feedback on draft reports. After reviewing the consultants' final reports, ACS created executive summaries for each country, highlighting relevant social and political trends that shape cancer control, describing the state of the public health system, analyzing the general state of cancer NGOs, distilling key details about each group, identifying the strongest groups, and providing recommendations for collaborative actions and potential next steps for working to build the capacity of cancer NGOs in each country, and regionally.

\section{Results}

\section{Overall strengths and weaknesses of cancer NGO sector in Latin America}

\section{General NGO institutional strengths}

The regional scan revealed that there are emerging NGOs in each country, and that, in general, NGOs in the region showed promise in the following areas:
Highly committed staff and volunteer base: In general, most cancer NGOs in the region, while small and under-funded, benefit from the strong commitment of core staff and a cadre of highly motivated volunteers. Many of the NGOs reported that volunteers devote their time and resources to cancer NGOs because of their own experiences confronting cancer as survivors, or supporting family members or friends during their illness. Furthermore, throughout the region, NGOs demonstrate recognition of the need to involve volunteers, especially survivors, in program design and implementation. Nonetheless, the majority of NGOs require further assistance in developing strategies to carry out survivorship programs, beyond simply utilizing survivors as volunteers or board members.

Expertise in pediatric cancer services: In terms of specialized areas of programmatic interest, a majority of NGOs surveyed focus exclusively on pediatric cancer, with an emphasis on supporting low-income children throughout their cancer treatment. Many of these childhood cancer organizations have developed expertise in managing shelter-based programs for children with cancer and their families, providing a range of services addressing medical care, nutritional needs, and psychological and emotional support for these families. Many also utilize a volunteer corps to provide specialized 
recreational and academic activities, to enhance the families' overall quality of life. Several NGOs in different countries have developed leadership in the procurement and distribution of necessary cancer treatment drugs for children through depots in larger cities, as well as provincial outposts.

Burgeoning breast cancer movement: In selected countries of the region, including Mexico and Brazil, among others, the NGO community has begun to develop networks of breast cancer survivors to provide emotional and practical support for women undergoing treatment for the disease. These survivors have broken the silence around the disease, and seek to assist others with the social, emotional and physical implications of living with breast cancer. Several groups have moved into the advocacy realm with initiatives to promote changes within the public health system to provide better quality of care and enhanced access to a range of treatment options, including state-of-the-art treatment drugs.

Emergence of innovative programs: Selected NGOs throughout the region have developed innovative programs in cancer control. For example, a handful of NGOs in Costa Rica have pioneered programs in the provision of palliative care, a critical area of cancer care that is largely neglected in most countries of the region. Other NGOs have developed specialized programs in prevention and early detection of cancer for underserved and hard-to-reach populations. For example, in Ecuador and Peru, among others, NGOs have employed mobile units and other strategies to provide early detection services to marginalized, impoverished communities. Another group of NGOs has developed expertise in legal strategies to promote cancer patient rights in the public health system (e.g., groups in Brazil).

Given the relative weakness of the NGO sector in cancer, the list of strengths is shorter and thinner than the weaknesses identified. This is a natural outcome of the weakness of the sector and helped ACS identify which best practices it would begin implementing capacity building programs which would extend the list of strengths over the long-run.

\section{General NGO institutional weaknesses}

The scan also underscored that while NGOs in the region have made some measure of progress in addressing cancer control, a multitude of obstacles must be overcome to strengthen NGO capacity, including the following:

Small size and limited community outreach: Regionally, most of the cancer NGOs are constrained by their small size and subsequent inability to conduct extensive com- munity outreach. Failure to establish strong links with other organized community groups diminishes the organizations' capacity for coalition-building to address cancer control policy, as well as their ability to reach target populations with appropriate information on prevention, early detection and access to treatment. Inadequate fundraising programs: Throughout the region, NGOs are constrained by a limited funding base, and lack capacity to develop strategic fundraising strategies. Without strategic fundraising, the organizations will never reach their full potential or enhance their institutional capacity. While some NGOs have realized a measure of success through specialized fundraising events, these efforts are generally part of a scattershot approach, rather than elements of a comprehensive fundraising strategy. Furthermore, most NGOs lack experience in diversifying donor portfolios and grantwriting at the national and international levels.

Lack of collaboration among groups: In general, cancer NGOs within the region do not actively seek out collaboration with other groups with similar or complementary missions. This lack of collaborative spirit can perhaps be explained by competition among groups for the limited available resources, or simply through preoccupation with their own programming and corresponding lack of awareness of others' initiatives. Regardless of the origins, a failure to coordinate efforts leads to overlapping missions among groups and hampers attempts to build a powerful constituency of cancer NGOs who are capable of effectively advocating for legislative changes related to cancer control.

Inability to develop advocacy-based programs: In many cases, cancer NGOs in the region are too overwhelmed by the continuous demands of patient services to expand or explore opportunities to develop patient advocacy or policy-level advocacy initiatives. NGO resources are stretched thin as groups attempt to fill the void in government-run services, through activities such as providing specialized care for children and adults undergoing treatment in major cities, maintaining drug banks to supply necessary treatment medications, or mounting educational campaigns on prevention and early detection for a variety of audiences, among others. This lack of focus on advocacy prevents the emergence of a vibrant community of NGOs capable of forming a strong coalition to address the inadequacies of government-run services at the policy-level.

Lack of strategic media relations approaches: The majority of NGOs in the region lack experience in cultivating productive relationships with the media, and developing effective communications programs. Failure to establish continuous contact with a variety of media outlets hinders efforts to mount strategic public educa- 
tion campaigns and to disseminate critical messages about cancer prevention, early detection and treatment, as well as opportunities to enhance the fundraising base of NGOs through increased visibility. Communications are further hampered by the unavailability of up-todate cancer statistics and information in Spanish or Portuguese.

Overall weak institutional capacity: Most of the NGOs surveyed demonstrated weaknesses in critical areas of institutional capacity, including staffing, management, evaluation and strategic planning. In a paradox that afflicts civil society worldwide; these liabilities both stem from and contribute to severe funding constraints. Their limited capacity stymies their abilities to adapt to changing policy environments and to become stronger stakeholders in the development of public policy affecting cancer control.

Failure to develop patient information dissemination strategies: Latin American cancer NGOs often fail to develop comprehensive strategies for patient information dissemination. Patients need reliable information on diagnosis and treatment options, as well as on ways of contacting available service agencies and other patients and survivors for practical and emotional support. Adequate information dissemination is a critical first step to fostering patient advocacy. Access to appropriate information enables patients to make informed decisions about their treatment options and can empower them to demand better quality of care and greater treatment options, once they are familiar with the standard of care, and educated about their rights.

Inadequate staff training: Given financial limitations, regional cancer NGOs are unable to devote adequate resources to staff training, which ultimately compromises service provision, and constrains the development of new programmatic areas, such as advocacy-based initiatives, due to low-level training.

Limited availability of information on prevention, detection and treatment: Cancer NGOs throughout the region remain largely dependent on government programs for informational and educational materials on cancer prevention, detection and treatment, and as a consequence often lack access to materials that are relevant for specific target groups, or are not up-to-date. When patients are not adequately informed, they will not be able to become their own advocates for high-quality services.

Lack of viable, active advocacy networks: Due to the small scale of most NGOs, and of NGO communities within countries, and a lack of collaboration among existing groups, the region has a paucity of viable, active advocacy networks related to cancer control. Furthermore, most groups have very limited experience or even knowledge of patient advocacy, with "survivorship," for the most part, emerging as a concept rather than a program reality among the majority of NGOs in the region. Similarly, most groups have little history of advocacy in the local or national policy arena.

\section{Next steps for Latin America}

The barriers to a vibrant cancer movement in Latin America lie in the youth and inexperience of the NGOs involved. Based on other successful health related movements, the biggest obstacle is the lack of involvement of survivors in creating the direction and strategy for Latin American NGOs. Although this is changing slightly with the higher survival rates of breast cancer patients, survivors and patients are mostly thought of as passive clients for cancer NGOs instead of leaders.

Both cancer control NGOs and cancer survivors themselves can benefit greatly when survivors become involved in cancer control, including advocacy, efforts. Some of the way survivors can become involved include:

- Providing support and information to patients and family members, and helping to get services to these people

- Starting and running support groups

- Giving presentations to the public, patients and health care providers on living with cancer

- Participating in, recruiting for, and running fundraising events and activities

- Speaking to the media and politicians to help change public opinion, reduce prejudice and discrimination, obtain improved treatment and health insurance coverage, and advocate for other systems-level changes

Survivors can be especially effective as advocates because they have their personal experience and commitment to draw upon. Their experience enables them to do the following:

- Empathize with other survivors

- Serve as role models for other survivors

- Put a face and story to a cause and rally support

- Add credibility to cancer control efforts

- Function as a profound reminder that cancer can be survived and that intervention can have a significant impact on the outcome of the disease as well as the quality of life of patients and their families

Cancer survivors experience their own benefits of being involved in cancer control efforts, including advocacy: 
- Survivors may be particularly motivated, dedicated and determined to make a difference because they want to create changes that will help both themselves and other survivors.

- Some want to help other survivors because they themselves received help; it can be fulfilling to use the knowledge, skills and experience they have gained to help others.

- Some seek to raise awareness about cancer so that more people are diagnosed earlier and so that both they and others receive better treatment by the public, people in their own lives and health care providers.

- In settings where diagnosis of cancer occurs at later stages, access to treatment is limited and mortality rates are higher, there may be smaller numbers of patients actually living with the disease to serve as advocates. In these cases, family members and friends of those with cancer, or of those who have died from cancer, may become even more impassioned to create change.

- Some may be motivated to influence funding streams for cancer-related research, or to advocate for changes related to patient rights, for example, to promote access to information to make informed decisions, to improve access to higher quality and more affordable services (treatment, prevention, early detection) or health insurance, or to safeguard the right of patients to obtain employment after treatment, etc.

NGOs are the only existing and critical link to involving survivors in cancer advocacy and therefore making the advocacy objective responsive to a grassroots, patient oriented movement. Therefore all of the interventions mentioned above are the stepping stones to advancing an advocacy agenda.

\section{Referencias}

I. World Health Organization. Non-communicable disease - A global priority, says the world health assembly. Retrieved May 20, 2008 from http://who.int/inf-pr-1998/en/pr98-39.html .

2. Mackay J, Jemal,A, Lee NC, Parkin DM. The Cancer Atlas. Georgia: American Cancer Society 2006: 78

3. Instituto Nacional de Cáncer - Ministerio de Salud. Organization summary. Retrieved May 20, 2008 from http://www.inca.gov.br/english/ 4. Markman, M. The increasingly complex world of cancer patient advocacy organizations. Retrieved May15,2008 from http://www.springerlink.com/ content/520p422r/843244w/fulltext.pdf

5. American Cancer Society. Cancer Facts \& Figures 2008. Retrieved December 15, 2008 from http://www.cancer.org/downloads/STT/ 2008CAFFfinalsecured.pdf. 